\title{
Oral Health Status of Children with Cerebral Palsy and its Relationship with Caregivers' Knowledge Related to Oral Health
}

\author{
Thulara R Daraniyagala ${ }^{1}$, Chandra K Herath ${ }^{2}$, Manjula S Gunasinghe ${ }^{3}$, Nandana Ranasinghe ${ }^{4}$, Methsiri B Herath ${ }^{5}$, \\ Primali R Jayasooriya ${ }^{6}$
}

\begin{abstract}
Objective: To assess the caries experience and periodontal status of a group of Sri Lankan children with cerebral palsy (CP) and to correlate it with caregivers' knowledge on oral hygiene/diseases.

Materials and methods: Ninety-three children with CP aged between 3 years and 18 years were included in the study. An oral examination was carried out to assess the dental caries and periodontal status by calibrated, trained dental surgeons. An interviewer-administered questionnaire comprising 10 questions was used to assess the oral health-related knowledge of caregivers. The results were analyzed statistically using Chisquare test $(p<0.05)$.

Results: The prevalence of caries in permanent and primary dentition was $10.75 \%$ and $55.91 \%$, respectively, while $100 \%$ showed gingivitis in varying severities. Dental history revealed that only $6 \%$ of the children brushed their teeth alone. When the knowledge was tested, majority of caregivers (93.5\%) knew that children should visit a dentist even without any complaint at least once in every 6 months; in contrast, $62 \%$ had never visited a dentist. Caregivers' level of knowledge is significantly correlated with poor oral health, as children with high level of caries in permanent dentition $(p=0.025)$ and severe gingivitis $(p=0.013)$ were most often accompanied by individuals with poor/moderate oral health-related knowledge.
\end{abstract}

Conclusion: Although majority of caregivers have moderate level of knowledge related to oral health, it does not invariably mean that they apply this knowledge to maintain good oral health in children. As gingivitis was observed in all patients, caregivers require instructions on how to perform good plaque control to maintain good periodontal health and reduce caries. Therefore, more educational programs are required to motivate caregivers to effectively practice oral health-related habits.

Keywords: Caregiver, Cerebral palsy, Dental caries, Gingivitis, Knowledge.

Journal of South Asian Association of Pediatric Dentistry (2019): 10.5005/jp-journals-10077-3031

\section{INTRODUCTION}

Cerebral palsy $(\mathrm{CP})$ is defined as a group of permanent disorders of the development of movement and posture, causing activity limitations, attributed to nonprogressive disturbances that occurred in the developing fetal or infant brain. ${ }^{1}$ According to the topographic classification, CP is classified as monoplegia, hemiplegia, diplegia, and quadriplegia. ${ }^{1}$ Research around the world have reported that the prevalence of $\mathrm{CP}$ range from 1.5 to more than 4 per 1,000 live births or children. ${ }^{2}$ However, to the best of our knowledge, no data are available on the prevalence of CP in Sri Lanka.

Oral health is multifaceted and includes the ability to speak, smile, smell, taste, touch, chew, swallow, and convey a range of emotions through facial expressions, with confidence and without pain, discomfort, and disease of the craniofacial complex. ${ }^{3}$ Children with CP are most often limited in their capacity to accomplish their normal activities of daily living. ${ }^{4}$ They are also most often unable to perform good oral hygiene practices due to oromotor dysfunction. Further, majority of the children with CP cannot communicate with their caregivers and may not be able to express feelings and understand the importance of satisfactory dental care. Therefore, caregivers, who include parents/grandparents, most often provide the principal, multifaceted tasks for the long-term management of these children, including maintaining oral hygiene.
${ }^{1}$ Department of Nursing, Faculty of Allied Health Sciences, University of Peradeniya, Peradeniya, Sri Lanka

${ }^{2}$ Department of Community Dental Health, Division of Paedodontics, Faculty of Dental Sciences, University of Peradeniya, Peradeniya, Sri Lanka

3,4 Department of Oral and Maxillofacial Surgery, Dental Teaching Hospital, Peradeniya, Sri Lanka

${ }^{5}$ Outpatient Department, Teaching Hospital, Peradeniya, Sri Lanka

${ }^{6}$ Department of Oral Pathology, Faculty of Dental Sciences, University of Peradeniya, Peradeniya, Sri Lanka

Corresponding Author: Chandra K Herath, Department of Community Dental Health, Division of Paedodontics, Faculty of Dental Sciences, University of Peradeniya, Peradeniya, Sri Lanka, Phone: +94 714467522, e-mail: ckh1719@yahoo.com

How to cite this article: Daraniyagala TR, Herath CK, Gunasinghe MS, et al. Oral Health Status of Children with Cerebral Palsy and its Relationship with Caregivers' Knowledge Related to Oral Health. J South Asian Assoc Pediatr Dent 2019;2(2):37-42.

Source of support: Nil

Conflict of interest: None

The main objective was to assess the caries experience and periodontal status of a group of Sri Lankan children with CP and to correlate it with caregivers' knowledge on oral hygiene/diseases.

(O) The Author(s). 20190pen Access This article is distributed under the terms of the Creative Commons Attribution 4.0 International License (https://creativecommons. org/licenses/by-nc/4.0/), which permits unrestricted use, distribution, and non-commercial reproduction in any medium, provided you give appropriate credit to the original author(s) and the source, provide a link to the Creative Commons license, and indicate if changes were made. The Creative Commons Public Domain Dedication waiver (http://creativecommons.org/publicdomain/zero/1.0/) applies to the data made available in this article, unless otherwise stated. 


\section{Materials and Methods}

The study was carried out among 93 medically diagnosed children with $\mathrm{CP}$ and their respective caregivers attending the Neurology Clinic at Rehabilitation Hospital, Digana, Sri Lanka, and Sirimavo Bandaranayake Specialized Children Hospital, Peradeniya, Sri Lanka.

Sample size was calculated using the National Oral Health Survey 2015-16 data from Sri Lanka, ${ }^{5}$ wherein the 12 -year-olds were found to be having caries and the prevalence rate was about $30 \%$. The assumption was that the children with CP will have more prevalence of caries, i.e., about 45\%. Keeping in mind the $\alpha$ error of 0.05 and power of study as $90 \%$, the sample size per the statistical software STATA came out to be 105 . However, in this study, only 93 children with CP attending outpatient departments in two large hospitals could be included.

Two pretested, interviewer-administered structured questionnaires were used to collect data related to actual oral hygiene practices of children with $\mathrm{CP}$ and caregivers' knowledge with reference to good oral hygiene practices and oral diseases, which comprised 10 questions. The caregivers' knowledge was categorized as follows after giving a score of 10 for each correct answer: low knowledge $<49 \%$, moderate knowledge $50-75 \%$, and good knowledge $>75 \%$

A dental examination was conducted to assess the caries experience and periodontal status of the patients by two calibrated and trained dental surgeons. Since patients were children with involuntary muscle control, a special chair was used for dental examination. Caries experience was determined by using dmft score (d, decay; m, missing due to caries; f, filled; $t$, teeth) for deciduous teeth, DMFT score ( $D$, decay; $M$, missing due to caries; $F$, filled; $T$, teeth) for permanent teeth, and Silness-Löe index was used to assess the periodontal health. Both the DMFT and dmft scores were categorized as follows: caries free $=0$, low severity $=1-2$, moderate severity $=$ $3-4$, and high severity $=5$ or $>5 .{ }^{6}$ After dental examination, the patients were referred to the Faculty of Dental Sciences, University of Peradeniya, for further management.

The questionnaire was translated to Sinhala and Tamil languages by a team fluent in Sinhala, Tamil, and English. It was validated in a previous study. ${ }^{7}$

According to the Silness-Löe index, gingivitis was categorized as follows:

No gingivitis $=0$, mild gingivitis $=1$, moderate gingivitis $=2$, and severe gingivitis $=>3 .{ }^{8}$

The collected data were entered into an Excel spreadsheet and was analyzed using the statistical software Statistical Package for Social Sciences version 22. The relationship between selected variables was analyzed using Chi-square, correlation, and one-way analysis of variance tests. A $p$ value less than or equal to 0.05 was considered as statistically significant.

Ethical clearance was obtained from the Ethical Review Committee of the Faculty of Allied Health Sciences, University of Peradeniya. The permission to collect data from the respective hospitals was obtained from the hospital directors after getting the ethical clearance. Informed written consent was obtained from the participants (caregivers) prior to data collection after explaining the purpose of the study.

\section{Results}

The study sample comprised CP children aged 3-18 years. Most of the children were accompanied by their mother $(n=76)$, while 12 and 5 children came with their father and grandparents, respectively. According to the topographic classification, 6.5\% ( $n=$ 6) of CP children were monoplegic, $21.5 \%(n=20)$ were diplegic, and nearly equal number of patients presented with hemiplegic $(32.5 \%$; $n=30)$ and quadriplegic $\mathrm{CP}(30.1 \% ; n=28)$. Nine patients were not classified. Of the 93 patients, 23 were diagnosed with epilepsy. Majority of the mothers (88.2\%) were housewives, while majority of fathers $(90.3 \%)$ were engaged in an occupation. Considering the monthly income of these families, most of them reported that earning low income.

Considering the total population, caries prevalence was $18 \%$ in permanent teeth and $57 \%$ in primary teeth. Out of $18 \%$ of children with caries in the permanent dentition, $6 \%$ of the children showed low caries levels; $6 \%$ moderate and $6 \%$ high levels of caries (Fig. 1). Nearly one third (31.2\%) of children presented with high level of caries in primary dentition, while $12.80 \%$ showed moderate level of caries and $13 \%$ had low level of caries (Fig. 1). The mean DMFT was $0.53 \pm 2.38$, and it was $3.74 \pm 5.01$ in dmft. The mean D (decayed teeth in permanent dentition) was $0.32 \pm 1.05$ and it was $3.49 \pm$ 4.75 in primary dentition. Only one child was reported with 19 filled permanent teeth, while only $3.22 \%$ had filled primary teeth. None of the children presented with extracted/missing teeth in permanent dentition, while three children reported extracted/missing teeth in primary dentition. Therefore, only $1.07 \%$ of children had received treatment of caries in permanent dentition, which was only $6.45 \%$ in primary dentition. Thus, $93.55 \%$ of children with CP were untreated for dental caries. A significant difference was observed between age and DMFT $(p<0.05)$ and no significant difference between age and dmft. All patients showed gingivitis at different degrees of severity with a mean Silness-Löe index score of $2.3 \pm 0.62$ (range 0.83-3.0). One hundred percent children with CP had gingivitis, with majority (51.6\%) having severe gingivitis. Less number of children $(8.6 \%)$ had mild gingivitis, while $39.8 \%$ had moderate gingivitis (Fig. 2). Regarding the treatment need with respect to periodontal health, all caregivers were found to require instructions on how to perform good plaque control.

Table 1 shows the number of patients in each subtype of $\mathrm{CP}$ based on their caries experience and periodontal health. No statistically significant differences were observed among CP patients when their caries experience and periodontal health was compared with the type of $C P\left(\chi^{2}\right.$ test $\left.p>0.05\right)$. With reference to the actual oral hygiene practices of children with CP (Table 2),

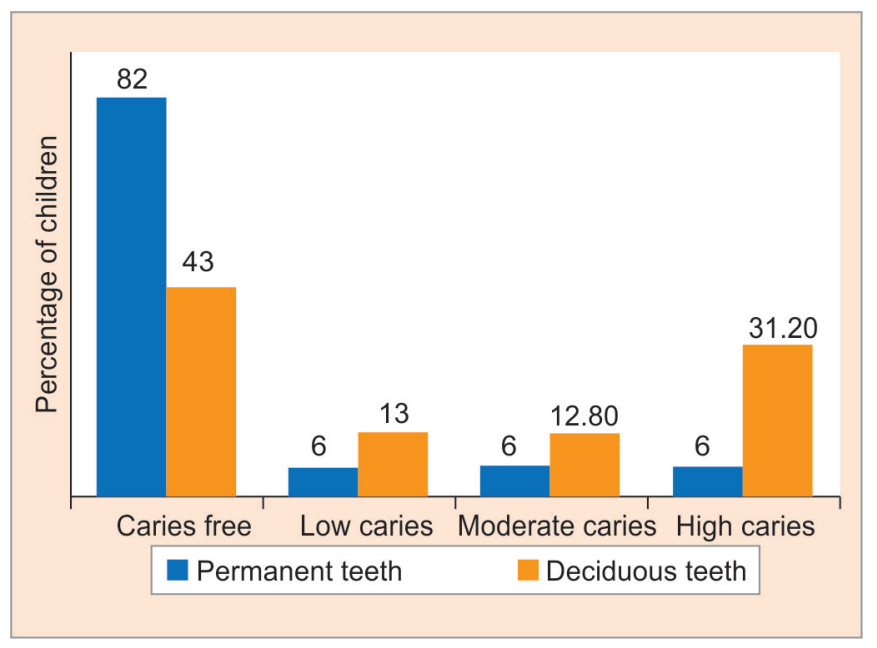

Fig. 1: Prevalence of caries in permanent and primary dentition 


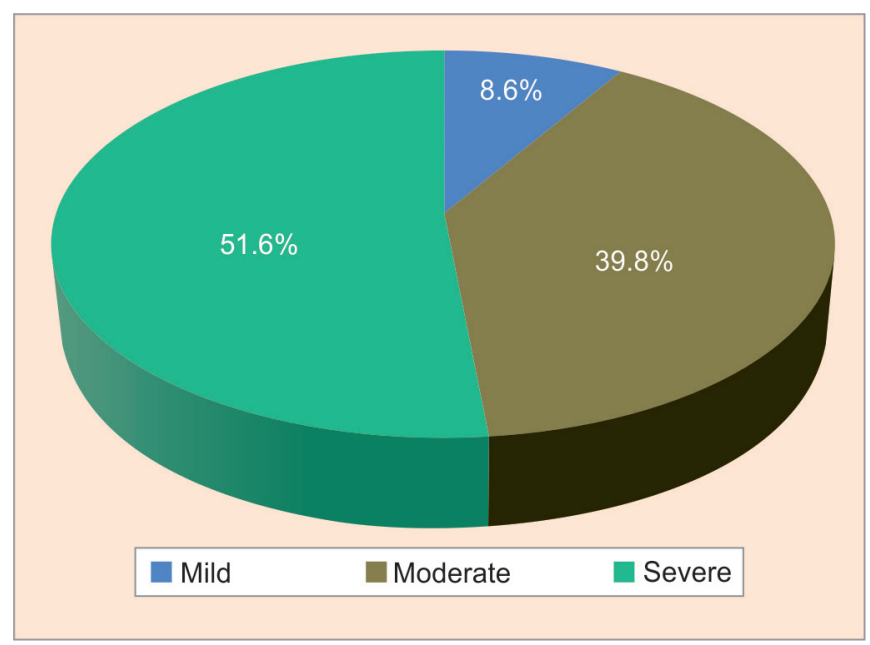

Fig. 2: Distribution of gingivitis

majority of the children [66.7\% (62)] had never visited a dentist. In all, 73.1\% (68) parents or caregivers brushed their children's teeth, while $20.4 \%$ (6) children brushed themselves and with support from others. However, $6.5 \%$ (19) children brushed only by themselves, will remove this as it can confused with above row. According to the results, brushing habits of these children were good. Caregivers were aware about the correct frequency of brushing. Majority (74.2\%) of the children had their teeth brushed twice a day. Sixtyeight (73.1\%) children used fluoride containing toothpaste and 18 (19.4\%) children used nonfluoride containing toothpaste such as Ayurvedic toothpaste.

Table 3 shows the caregivers' knowledge with respect to oral health. In contrast to the actual practice, majority of participants (93.5\%) knew that they should visit the dentist even without any complaint at least once in every 6 months, but $66.7 \%$ of them had not visited a dentist even once. Only a few parents (4.3\%) knew that gum diseases may cause strokes and heart attacks. Less than half of the parents (29\%) believed that dental caries is a familial disease. Majority (80.6\%) knew that plaque is the main cause for gum diseases. In addition, very few parents (20.4\%) knew that recommended brushing time for an adult is 2 minutes. Based on the total score that each caregiver obtained for his or her knowledge was categorized as poor, moderate, and good. Accordingly, only $3.2 \%$ parents had good knowledge, while $66.7 \%$ of the caregivers had moderate and the rest (30.1\%) had poor level of knowledge (Fig. 3). Further, according to the Cramer's V correlation, there was a positive weak association between the overall oral healthrelated knowledge and education level of the caregivers (Cramer's $V=0.343, p=0.001)$. In other words, the educational level of the caregivers influenced their knowledge on oral health as well. No significant association was found between the overall knowledge and age of the caregiver and overall knowledge and ethnicity of the caregiver.

Tables 4 and 5 show the number of CP children with different severities of caries and periodontal disease, which were classified based on the level of knowledge of the caregiver. Accordingly, statistically significant differences were observed with caries levels in permanent teeth $(p=0.025)$ and severity of gingivitis ( $p$ $=0.013$ ) when compared with oral health-related knowledge of the caregiver. Although the same significance was not seen when caries level in deciduous teeth was considered, it was very close to reaching significance with a $p$ value of 0.08 (Table 6).

\section{Discussion}

This cross-sectional study aimed at evaluating the oral health status and awareness of caregivers regarding oral health in children with $\mathrm{CP}$. When considering the sociodemographic data, the literature states that the incidence of CP is higher in males. ${ }^{9}$ However, the present study did not show this difference. The number of working mothers was found to be significantly lower (10.8\%) in this study. This may be explained by the fact that mothers of children with $\mathrm{CP}$ do not have the time to work and would rather stay at home to take care of their child. These findings were in agreement with the findings of Brehaut et al. ${ }^{10}$ Most of the children included in the study were hemiplegic similar to the results of Abanto et al. ${ }^{6}$

Children with $\mathrm{CP}$ due to their neurological dysfunction may not have the ability to take care of their oral health. ${ }^{11-13}$ Sri Lankan National Oral Health Survey 2015/2016 reported the prevalence of early childhood caries among 5 -year-olds as $63.1 \%$ in primary dentition, $1.5 \%$ in permanent dentition, and $30.4 \%$ and $41.5 \%$ in 12-year-olds and 15-year-olds in the general population, respectively. ${ }^{5}$ Prevalence of caries in primary dentition was $57 \%$ and $18 \%$ in permanent dentition for children with CP in the present study, which is lower than that in the general population. Similarly, Diéguez-Pérez et al. ${ }^{14}$ also reported that they observed lower levels of dental caries among children with CP. In contrast, Huang et al. ${ }^{15}$

Table 1: Caries and periodontal status of children with different types of cerebral palsy

\begin{tabular}{|c|c|c|c|c|c|}
\hline Oral health status & Monoplegia (\%) & Diplegia (\%) & Hemiplegia (\%) & Quadriplegia (\%) & Other (\%) \\
\hline \multicolumn{6}{|l|}{ Caries (dmft) } \\
\hline Low caries & 16.66 & 15 & 13.33 & 10.34 & 11.11 \\
\hline Moderate caries & 16.66 & 10 & 10 & 6.89 & 22.22 \\
\hline Severe caries & 16.66 & 35 & 36.66 & 17.24 & 22.22 \\
\hline \multicolumn{6}{|l|}{ Caries (DMFT) } \\
\hline Low caries & 0 & 0 & 6.66 & 0 & 0 \\
\hline Moderate caries & 16.6 & 0 & 0 & 6.89 & 11.11 \\
\hline Severe caries & 0 & 0 & 6.66 & 3.44 & 0 \\
\hline \multicolumn{6}{|c|}{ Gingivitis (plaque index) } \\
\hline Mild & 0 & 15 & 10 & 3.45 & 11.11 \\
\hline Moderate & 50 & 70 & 20 & 34.48 & 33.33 \\
\hline Severe & 50 & 15 & 70 & 51.72 & 55.55 \\
\hline
\end{tabular}


found that the prevalence of caries in their sample was $75 \%$, with the mean of decayed teeth of permanent dentition $3.43 \pm 4.75$, and it was $0.32 \pm 1.05$ in the present study. The reason for higher prevalence of caries in permanent dentition may be due to the heavy food intake, which are rich in cariogenic food during the growth spurt. However, further studies are needed to arrive at conclusion regarding whether the caries levels are actually lower in children with CP compared to the general population of healthy children in Sri Lanka.

According to the results of our study, children with CP had more decayed ( $9.6 \%$ in permanent dentition and $55.91 \%$ in primary dentition) teeth and fewer filled teeth in permanent dentition $(1.07 \%)$ and $3.22 \%$ in primary dentition. The higher percentage of untreated dental caries found in this study is similar to some studies. ${ }^{4,15-18}$ Caries may occur in children with CP due to retention of biofilm associated with oromotor dysfunction. It is also very important to educate caregivers to seek treatment of caries in deciduous dentition as otherwise it would give rise to problems such as malocclusion in the permanent dentition.

According to the results of our study, most of the children (84.9\%) had incompetent lips. Previous studies ${ }^{19}$ showed that gingival bleeding and gingivitis were higher in children with CP.

Table 2: Actual oral hygiene practices of children with cerebral palsy

\begin{tabular}{lcc}
\hline & Frequency $(n=93)$ & Percentage \\
\hline Visit to dentist & 31 & 33.30 \\
Yes & 62 & 66.70 \\
Never & & \\
Who brushes child's teeth & 68 & 73.10 \\
Parent/caregiver & 6 & 6.50 \\
Child & 19 & 20.40 \\
Parent and child & 16 & \\
How often does the child brush teeth & 17.20 \\
Once a day/occasionally & 69 & 74.20 \\
Twice a day & 8 & 8.60 \\
More than twice a day & 68 & \\
Toothpaste: fluoride containing or not & 73.10 \\
Yes & 18 & 19.4 \\
No & & \\
\hline
\end{tabular}

This high frequency may be due to the same factors related to dental caries, which led to biofilm buildup. ${ }^{20,21}$ In this sample, majority of children (51.6\%) had severe gingivitis. Most important factors in maintenance of oral hygiene are frequency and effectiveness of toothbrushing. Although parents reported that children had their teeth brushed twice a day, it may be suggested that the caregiver and or the child may have used the incorrect method of toothbrushing. Findings of Nouri was unlike our study in which majority of children showed mild gingivitis. However, another study reported that $86 \%$ children had mild to moderate gingivitis. ${ }^{15}$ Nouri reported that majority of children showed mild gingivitis, whereas Cardoso et al. reported that $86 \%$ children had mild to moderate gingivitis. ${ }^{16}$ Therefore, based on the results of the present study, it can be concluded that advice related to correct brushing techniques and monitoring are required to reduce gingivitis in patients. In our sample, $66.7 \%$ of children had never visited a dentist. Similarly, in a study conducted in India it was also found that majority (67.2\%) of children were not seen by a dentist. ${ }^{21}$

In dental literature, the knowledge of mothers/caregivers has been reported to be a significant factor in the prevention of oral problems. ${ }^{22}$ Majority (93.5\%) of mothers agreed that they should visit a dentist even without any complaint at least once every 6 months. However, nearly two third (66.7\%) of the

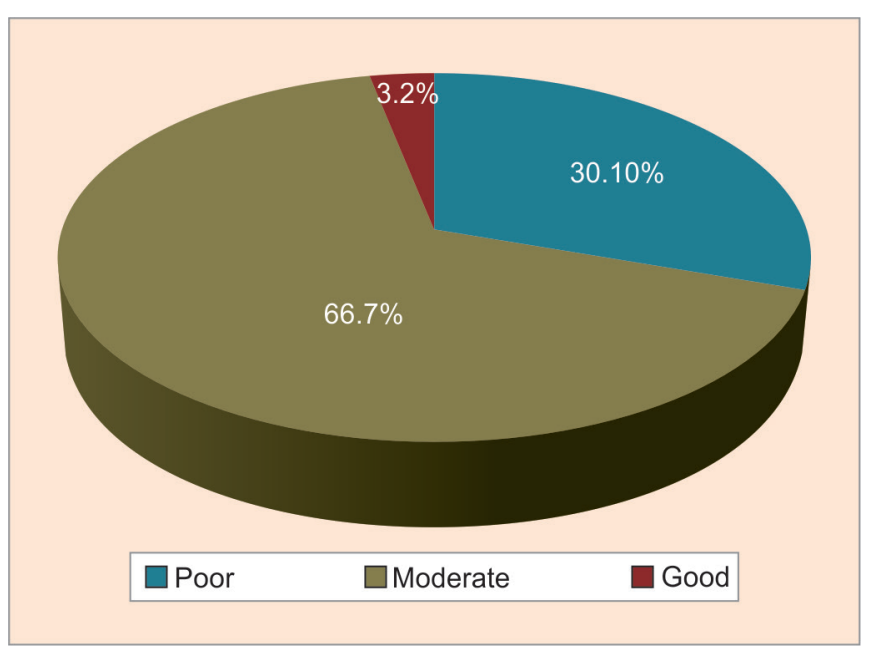

Fig. 3: Distribution of overall knowledge

Table 3: Evaluation of caregivers' knowledge related to oral health

\begin{tabular}{|c|c|c|c|c|c|c|}
\hline \multirow[b]{2}{*}{ Statement } & \multicolumn{2}{|c|}{ Correct } & \multicolumn{2}{|c|}{ Wrong } & \multicolumn{2}{|c|}{ Don't know } \\
\hline & $n$ & (\%) & $n$ & (\%) & $n$ & (\%) \\
\hline $\begin{array}{l}\text { Should visit the dentist even without any complaint at least once in every } \\
6 \text { months }\end{array}$ & 87 & 93.50 & 4 & 4.30 & 2 & 2.20 \\
\hline Tooth decay can be prevented from brushing of teeth & 81 & 87.10 & 7 & 7.50 & 5 & 5.40 \\
\hline Tooth decay is a familial disease & 27 & 29 & 38 & 40.90 & 28 & 30.10 \\
\hline Fluoride prevents tooth decay and protects teeth & 23 & 24.70 & 12 & 12.90 & 57 & 74.2 \\
\hline Tooth brush with soft bristles is the most suitable toothbrush to brush teeth & 58 & 62.40 & 27 & 29 & 8 & 8.60 \\
\hline Gum diseases may cause stroke and heart attack & 4 & 4.30 & 14 & 15.10 & 75 & 80.60 \\
\hline Plaque is the main cause for gum diseases & 75 & 80.60 & 3 & 3.20 & 15 & 16.10 \\
\hline Tooth decay is a communicable disease that is transmitted from parents to child & 31 & 33.30 & 42 & 45.20 & 20 & 21.50 \\
\hline Tooth decay cannot be prevented & 28 & 30.10 & 64 & 68.80 & 1 & 1.10 \\
\hline Recommended brushing time for an adult is 2 minutes & 19 & 20.40 & 69 & 74.20 & 5 & 5.40 \\
\hline
\end{tabular}


Table 4: Relationship between level of knowledge of the caregiver and the oral health status of the child

\begin{tabular}{lccl}
\hline & \multicolumn{3}{c}{ Knowledge } \\
\cline { 2 - 4 } Oral health status & Low & Moderate & Good \\
\hline Caries experience in primary dentition & & 2 \\
Caries free & 15 & 23 & 0 \\
Low caries & 5 & 8 & 0 \\
Moderate caries & 2 & 8 & 1 \\
Severe caries & 7 & 21 & \\
Caries experience in permanent dentition & & 0 \\
Caries free & 9 & 22 & 0 \\
Low caries & 2 & 1 & 1 \\
Moderate caries & 1 & 1 & 0 \\
Severe caries & 1 & 2 & \\
Gingivitis & & & 0 \\
Mild & 5 & 3 & 2 \\
Moderate & 14 & 23 & \\
Severe & 9 & 36 & \\
\hline
\end{tabular}

children had never visited a dentist. Therefore, there seem to be a gap between knowledge and actual practices. As such it is recommended that further oral health-related education and motivation on importance of dental care and practices may be required. In this study, only $33.3 \%$ of mothers knew that tooth decay is a communicable disease that is transmitted from parents to child. This finding was in agreement with the findings of Sultan, Ain, and Gowhar who stated that most of the mothers do not know about this fact mentioned above. Only $40.9 \%$ of mothers had knowledge about the fact that tooth decay is not a familial disease and $68.8 \%$ knew that tooth decay can be prevented. Majority of mothers (74.2\%) did not know that fluoride is helpful to prevent tooth decay and protect teeth. This findings of our study support the study of Sultan, Ain, and Gowhar who found that majority of mothers did not know that fluoride prevent tooth decay. Low level of knowledge (20.4\%) was observed about the recommended brushing time for an adult.

Gurunathan et al. ${ }^{23}$ had found that mothers with lesser education levels are not aware of the reason for bleeding gums. A study conducted in Chennai found that there was a significant difference between responses regarding the awareness of oral health between educated and uneducated mothers. ${ }^{23}$ In our study, we found a statistically significant association between the overall knowledge and educational level of the caregiver $(p<0.01)$. However, in our study, mother's age and ethnicity had no significant correlation with oral health knowledge. In contrast, Akpabio et al. ${ }^{24}$ showed a significant association between age and knowledge/ prevention of disease and consequences of poor oral health. The findings of this study may be useful to raise the awareness and rectify the incorrect understanding among caregivers regarding oral health.

Some factors limit the ability to generalize the findings to all children with CP in Sri Lanka. The sample size was marginally lower than the calculated sample size due to the limitation of time period to conduct this study. The fact that a control group of healthy children could not be recruited due to time constraints is another limitation. In addition, as most of the children with CP had to participate in occupational therapy, physiotherapy, and speech therapy, all on the same day, mothers were reluctant to linger in
Table 5: Statistical analysis showing relationship between caries and periodontal status and the knowledge level of the caregiver

\begin{tabular}{llll}
\hline & \multicolumn{3}{c}{ Knowledge } \\
\cline { 2 - 4 } Oral health status & $\begin{array}{l}\text { Chi-square } \\
\text { value }\end{array}$ & $d f$ & p value \\
\hline $\begin{array}{l}\text { Caries experience in primary dentition } \\
\text { Caries free }\end{array}$ & 11.10 & 6 & 0.085 \\
Low caries & & & \\
Moderate caries & & & \\
Severe caries & & & \\
Caries experience in permanent & & & \\
dentition & & & \\
Caries free & 14.38 & 6 & $0.025^{*}$ \\
Low & & & \\
Moderate & & & \\
Severe & & & \\
Gingivitis & & & \\
Mild & & & \\
Moderate & & & \\
Severe & & & \\
\hline
\end{tabular}

${ }^{*} p<0.05$ statistically significant

Table 6: Caries experience of the children with cerebral palsy

\begin{tabular}{lrrll}
\hline Age & Mean DMFT & Mean dmft & $\begin{array}{l}\text { Without } \\
\text { caries (\%) }\end{array}$ & $\begin{array}{l}\text { With caries } \\
\text { (\%) }\end{array}$ \\
\hline $3-6$ & - & $5.13 \pm 5.60$ & 33.33 & 66.66 \\
$7-12$ & $0.44 \pm 1.19$ & $16 \pm 3.45$ & 50 & 50 \\
$>12$ & $5 \pm 7.35$ & $0.29 \pm 0.76$ & 28.57 & 71.42 \\
Total effect & $3.74 \pm 5.01$ & $0.53 \pm 2.38$ & 29 & 71 \\
\hline
\end{tabular}

the clinic for the data collection required to complete the study and also it was difficult to assess the children with CP due to their uncontrollable behaviors. However, despite these limitations, it seems worthwhile to consider these findings and start a process of developing strategies to improve oral health in especially vulnerable populations.

\section{Conclusion}

Based on the results of this study, children with CP have higher number of decayed teeth and a fewer number of missing (extracted) and filled teeth. It can be concluded that $100 \%$ treatment needs was required for gingivitis. According to the findings of our study, it can be concluded that caregivers of children with $\mathrm{CP}$ have moderate level of knowledge about oral health. However, as the level of knowledge does not correspond to the actual practices, more educational programs are needed to increase the correct oral practices of caregivers on oral health. In addition, it can be stated that, it is important to educate mothers to seek oral healthcare services at the correct time for their children in order to prevent worsening of oral health-related problems in this vulnerable group of children.

\section{Recommendations}

The findings of our study may help in planning, designing, and conducting health educational programs intended to create 
awareness of oral health among caregivers of children with special needs. The treatment needs identified in the study are quite significant, and it shows that individuals with disabilities are still not able to access required oral care. It addition, it would be better to train and educate the caregivers in oral hygiene and practices. The results of this study may help dental surgeons while planning and conducting treatment strategies and new clinical protocols for disabled children. Healthcare professionals should be aware of the importance of early prevention and interventions of oral problems by screening and early detection of oral symptoms. It is also beneficial to have dentists visit the institutions or clinics where the children are followed up on a regular basis to provide educational programs and oral examinations.

\section{Author Contributions}

EMUCK Hearth contributed to concept and design of study; PPTR Daraniyagala; PPTR Daraniyagala, SMN Ranasinghe, MS Gunasinghe and HMMB Herath performed acquisition of data; PPTR Daraniyagala, EMUCK Hearth and PR Jayasooriya performed data analysis and interpretation of data; PPTR Daraniyagala performed drafting the article; EMUCK Hearth and PR Jayasooriya performed revising it critically for important intellectual content; PR Jayasooriya performed final approval of the version to be published.

\section{Statement}

This is to certify that the manuscript entitled "Oral Health Status of Children with Cerebral Palsy and its Relationship with Caregivers' Knowledge Related to Oral Health" has been read and approved by all authors. Further, each author confirms that the manuscript represents honest work and that it has not been published in any other form.

\section{References}

1. Sehrawat N, Marwaha M, Bansal K, et al. Cerebral palsy: a dental update. Int J Clin Pediatr Dent 2014;7(2):109. DOI: 10.5005/ jp-journals-10005-1247.

2. Stavsky M, Mor O, Mastrolia SA, et al. Cerebral palsy-trends in epidemiology and recent development in Prenatal mechanisms of disease, treatment, and prevention. Front Pediatr 2017;5:21.

3. Glick M, Williams DM, Kleinman DV, et al. A new definition for oral health developed by the FDI World Dental Federation opens the door to a universal definition of oral health. J Public Health Dent 2017;77:3-5. DOI: 10.1111/jphd.12213.

4. Nouri S, Alaki. S, Ashiry. E. Oral health in children with cerebral palsy. Oral Health Dent Manag 2014;13:4.

5. National Oral Health Survey Sri Lanka 2015-2016. Colombo: Ministry of Health, Nutrition and Indigenous Medicine (Sri Lanka); 2018.

6. Abanto J, Carvalho TS, Bönecker M, et al. Parental reports of the oral health-related quality of life of children with cerebral palsy. BMC Oral Health 2012;12:15. DOI: 10.1186/1472-6831-12-15.

7. Hearth CK, Perera IR, Jayasooriya PR. The socio-demographic profile of children affected by amelogenesis imperfecta and its impact on families: a pilot study based on children attending a pedodontic clinic in Sri Lanka. J South Asian Assoc Ped Dent 2018; 1. DOI: 10.5005/ jp-journals-10077-3004.

8. Dholam KP, Gurav S, Dugad J, et al. Correlation of oral health of children with acute leukemia during the induction phase. Indian J Med Paediatr Oncol 2014;35(1):36-39. DOI: 10.4103/0971-5851.133717.

9. Jarvis S, Glinianaia SV, Arnaud C, et al. Case gender and severity in cerebral palsy varies with intrauterine growth. Arch Dis Child 2005;90(5):474-479. DOI: 10.1136/adc.2004.052670.

10. Brehaut JC, Kohen DE, Raina P, et al. The health of primary caregivers of children with cerebral palsy: how does it compare with that of other Canadian caregivers? Pediatrics 2004;114(2):182-191. DOI: 10.1542/ peds.114.2.e182.

11. Dougherty NJ. A review of cerebral palsy for the oral health professional. Dent Clin North Am 2009;53(2):329-338. DOI: 10.1016/ j.cden.2008.12.001.

12. Santos MTBR, Guare RO, Celiberti $P$, et al. Caries experience in individuals with cerebral palsy in relation to oromotor dysfunction and dietary consistency. Spec Care Dentist 2009;29(5):198-203. DOI: 10.1111/j.1754-4505.2009.00092.x.

13. De Carvalho RB, Mendes RF, Prado RR. Jr, et al. Oral health and oral motor function in children with cerebral palsy. Spec Care Dent 2011;31(2):58-62. DOI: 10.1111/j.1754-4505.2011.00180.x.

14. Diéguez-Pérez M, de Nova-García MJ, Mourelle-Martínez MR, et al. Oral health in children with physical (cerebral palsy) and intellectual (Down syndrome) disabilities: systematic review I. J Clin Exp Dent 2016;8(3):e337-e343.

15. Huang ST, Hurng SJ, Liu HY, et al. The oral health status and treatment needs of institutionalized children with cerebral palsy in Taiwan. J Dent Sci 2010;5(2):75-89. DOI: 10.1016/S1991-7902(10)60012-8.

16. Cardoso AM, Gomes LN, Silva CRD, et al. Dental caries and periodontal disease in Brazilian children and adolescents with cerebral palsy. Int J Environ Res Public Health 2014;12(1):335-353. DOI: 10.3390/ ijerph120100335.

17. Oredugba FA. Comparative oral health of children and adolescents with cerebral palsy and controls. J Disab Oral Health 2011;12:68.

18. Riberto M, Miyazaki MH, Jucá SS, et al. Validação da versãobrasileira da Medida de Independência Funcional. Acta fisiátrica 2004;11(2): 72-76.

19. Guare RDO, Ciampioni AL. Prevalence of periodontal disease in the primary dentition of children with cerebral palsy. J Dent Child 2004;71(1):27-32.

20. Du RY, McGrath C, Yiu CK, et al. Health-and oral health-related quality of life among preschool children with cerebral palsy. Qual Life Res 2010;19(9):1367-1371. DOI: 10.1007/s11136-010-9693-6.

21. Ain TS, Gowhar O, Sultan S, et al. Prevalence of oral mucosal lesions and associated habits in Kashmir, India. Int J Res Med Sci 2016;4(8):3525-3530. DOI: 10.18203/2320-6012.ijrms20162324.

22. Maharani DA, Rahardjo A. Mothers' dental health behaviors and mother-child's dental caries experiences: study of a suburb area in Indonesia. Makara J Health Res 2013; 72-76.

23. Gurunathan D, Moses J, Arunachalam SK. Knowledge, attitude, and practice of mothers regarding oral hygiene of primary school children in Chennai, Tamil Nadu, India. Int J Clin Pediatr Dent 2018;11(4):338. DOI: 10.5005/jp-journals-10005-1535.

24. Akpabio A, Klausner CP, Inglehart MR. Mothers'/guardians' knowledge about promoting children's oral health. Am Dent Hyg 2008;82(1): $12-12$. 